\title{
Hyaluronan concentration and size distribution in human knee synovial fluid: variations with age and cartilage degeneration
}

Michele M. Temple-Wong ${ }^{1}$, Shuwen Ren ${ }^{1}$, Phu Quach ${ }^{1}$, Bradley C. Hansen ${ }^{1}$, Albert C. Chen ${ }^{1}$, Akihiko Hasegawa ${ }^{2}$, Darryl D. D'Lima², Jim Koziol ${ }^{2}$, Koichi Masuda ${ }^{4}$, Martin K. Lotz ${ }^{2}$ and Robert L. Sah ${ }^{1,4,5^{*}}$ (1)

\begin{abstract}
Background: One potential mechanism for early superficial cartilage wear in normal joints is alteration of the lubricant content and quality of synovial fluid. The purpose of this study was to determine if the concentration and quality of the lubricant, hyaluronan, in synovial fluid: (1) was similar in left and right knees; (2) exhibited similar age-associated trends, whether collected postmortem or antemortem; and (3) varied with age and grade of joint degeneration.

Methods: Human synovial fluid of donors (23-91 years) without osteoarthritis was analyzed for the concentrations of protein, hyaluronan, and hyaluronan in the molecular weight ranges of 2.5-7 MDa, 1-2.5 MDa, 0.5-1 MDa, and 0.03-0.5 MDa. Similarity of data between left and right knees was assessed by reduced major axis regression, paired t-test, and Bland-Altman analysis. The effect of antemortem versus postmortem collection on biochemical properties was assessed for age-matched samples by unpaired $t$-test. The relationships between age, joint grade, and each biochemical component were assessed by regression analysis.

Results: Joint grade and the concentrations of protein, hyaluronan, and hyaluronan in the molecular weight ranges of 2.5-7 MDa, 1-2.5 MDa, and 0.5-1 MDa in human synovial fluid showed good agreement between left and right knees and were similar between age-matched patient and cadaver knee joints. There was an age-associated decrease in overall joint grade $(-15 \% /$ decade) and concentrations of hyaluronan $(-10.5 \% /$ decade), and hyaluronan in the molecular weight ranges of 2.5-7 MDa (-9.4\%/decade), 1-2.5 MDa (-11.3\%/decade), 0.5-1 MDa (-12.5\%/decade), and $0.03-0.5 \mathrm{MDa}(-13.0 \% /$ decade). Hyaluronan concentration and quality was more strongly associated with age than with joint grade.
\end{abstract}

Conclusions: The age-related increase in cartilage wear in non-osteoarthritic joints may be related to the altered hyaluronan content and quality of synovial fluid.

Keywords: Hyaluronan, Synovial fluid, Aging, Degeneration

\footnotetext{
*Correspondence: rsah@ucsd.edu

'Department of Bioengineering, University of California-San Diego, 9500

Gilman Drive, Mail Code 0412, La Jolla, CA 92093-0412, USA

${ }^{4}$ Department of Orthopaedic Surgery, University of California-San Diego, 9500

Gilman Drive, Mail Code 0412, La Jolla, CA 92093-0412, USA

Full list of author information is available at the end of the article
} 


\section{Background}

Synovial fluid (SF) functions as a biological lubricant and biochemical pool of nutrients and regulatory cytokines. It reduces friction at cartilage-cartilage interfaces in the boundary mode of lubrication [1]. The early cartilage wear that occurs in macroscopically normal joints with aging and is evident at the superficial zone [2] suggests that the wear-protective function of SF and wearresistance of cartilage are altered with aging and may lead to the development of osteoarthritis (OA). One possible mechanism for these changes in the knee is ageand disease-related deterioration of SF lubricant quality. Such diminished SF lubrication has been observed following acute injuries in horses [3] and humans [4], and in experimental models of osteoarthritis in rabbits [5] and guinea pigs [6]. The elucidation of situations in which SF lubrication properties and lubricant biomolecules are diminished could lead to the development of treatments to correct such lubrication deficiency.

A primary lubricant molecule in SF is hyaluronan (HA), interacting with and adsorbing to the articular surface [7]. $\mathrm{HA}$ is present in SF as a polydisperse polymer of repeating disaccharides of $\mathrm{N}$-acetyl-glucosamine and glucuronic acid, connected exclusively by $\beta$-linkages of up to $20 \mathrm{MDa}$ [8]. In the boundary mode of lubrication, the cartilage-oncartilage (but not cartilage-on-glass [9] or mica-on-mica [10]) friction-lowering properties of HA are dependent on its concentration [11] and molecular mass $\left(\mathrm{M}_{\mathrm{r}}\right)$ [3], with lubrication properties being better for higher- $\mathrm{M}_{\mathrm{r}}$ forms of HA. The HA concentration in human SF (hSF) ranges widely, from 1 to $4 \mathrm{mg} / \mathrm{ml}[12,13]$. Few studies have described the age-related variations in HA concentration or size in hSF. hSF HA concentration has been reported as changing little with age or tending to decrease between 28 and 40 years of age and remaining at a low level beyond that age $[13,14]$, with little known about the possible effects of age- and OA-related degeneration. In OA compared to normal knees, the HA concentration is lower $[12,15]$, with a shift to lower $M_{r}$ forms of HA $[12,16]$. However, the ageassociated changes in the content and $\mathrm{M}_{\mathrm{r}}$ of $\mathrm{HA}$ in hSF from knee joints without OA are unclear.

The hypothesis tested in this study was that the HA concentration and $\mathrm{M}_{\mathrm{r}}$ distribution in hSF fluid varies with adult age and cartilage degeneration. Thus, the aims of this study were to determine if hSF concentration of HA as well as protein, and $M_{r}$ distribution of HA: (1) differed between left and right knees of individual donors; (2) differed between cadaveric donors and patients; and varied with (3) age and (4) grade of joint degeneration.

\section{Methods}

\section{Study design}

To address the four aims, hSF was analyzed from knee joints without OA. hSF was aspirated from one or both knee joints ( $\mathrm{n}=48$ joints) of cadaveric human donors ( $\mathrm{n}=28$ donors) within 72 hours of death. The donors were without OA based on exclusion criteria of a history of knee arthritis or trauma, body mass index (BMI) $>30 \mathrm{~kg} / \mathrm{m}^{2}$, and macroscopic evidence of osteophytes, full-thickness erosion, or severe degeneration. Donors were selected to reflect an approximately even distribution of age and gender, with age from $23-91$ years $(61 \pm 19$ years, mean \pm standard deviation (SD)), 12 male and 16 female donors, and BMI of $12-30 \mathrm{~kg} / \mathrm{m}^{2}\left(25 \pm 8 \mathrm{~kg} / \mathrm{m}^{2}\right)$. hSF was obtained within 72 hours of death ( $48 \pm 15$ hours). In addition, data were obtained about hSF obtained previously in vivo from consenting patients of an Institutional Review Board approved study at the University of California, San Diego [4], from non-injured and non-OA knees of a subset of patients that ranged in age from $25-59$ years ( $45 \pm 15$ years) and included six male and two female donors.

Each of these hSF samples was analyzed for the concentrations of protein $\left(\mathrm{C}_{\mathrm{Pro}}\right)$, $\mathrm{HA}\left(\mathrm{C}_{\mathrm{HA}}\right)$ and $\mathrm{HA}$ in $\mathrm{M}_{\mathrm{r}}$ ranges of 2.5-7 MDa $\left(\mathrm{c}_{\mathrm{HA}(2.5-7 \mathrm{MDa})}\right), 1-2.5 \mathrm{MDa}\left(\mathrm{c}_{\mathrm{HA}(1-2.5 \mathrm{MDa})}\right), 0.5-$ $1 \mathrm{MDa}\left(\mathrm{c}_{\mathrm{HA}(0.5-1 \mathrm{MDa})}\right)$ and $0.03-0.5 \mathrm{MDa}\left(\mathrm{c}_{\mathrm{HA}(0.03-0.5 \mathrm{MDa})}\right)$.

The similarity between left and right knees of overall joint grade and hSF properties was analyzed by reduced major axis regression (with one delete jack-knife estimates of the slope, intercept, regression coefficient, and associated standard errors) $[17,18]$, paired t-tests, and Bland-Altman analysis [19].

To determine how hSF compared between cadaver donor and patient knees, age-matched patient and cadaver hSF samples were compared. The effect of hSF

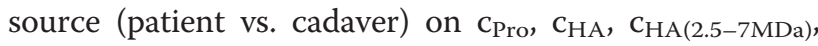
$\mathrm{C}_{\mathrm{HA}(1-2.5 \mathrm{MDa})}, \mathrm{C}_{\mathrm{HA}(0.5-1 \mathrm{MDa})}$, and $\mathrm{C}_{\mathrm{HA}(0.03-0.5 \mathrm{MDa})}$ of agematched hSF samples was assessed by analysis of variance with age as a covariate.

The effect of age and stage of joint degeneration on the concentrations of protein and HA and HA $\mathrm{M}_{\mathrm{r}}$ distribution were assessed. Because of the similarity of several HA properties between left and right knees, data from left and right knees were not treated as independent measures, and further analyses were performed on the average of data from left and right knees of the same donor. Also, due to the similarity between patient and cadaver hSF samples, data from patient and cadaver hSF were analyzed together to assess the effect of age and joint degeneration on biochemical measures. Univariate linear regression was performed to assess the effect of age on joint grade as well as the effect of age on each biochemical measure and the effect of joint grade on each biochemical measure. To further assess the effect of age on the fraction of HA in each $M_{r}$ bin, a beta regression model was applied [20]. To assess whether each HA biochemical property was dependent on both joint grade and age, multivariate regression with the backward elimination procedure was performed. 


\section{Macroscopic joint grading}

Joints were screened by macroscopic observation. An overall joint grade was determined for each cadaver knee joint as a sum of modified Outerbridge macroscopic grades (1-4) of each of nine regions of each condyle, three regions on the trochlea, nine regions of each tibial plateau, and nine regions on the patella, as described by the International Cartilage Repair Society (ICRS) [21, 22]. ICRS scores can thus range from 48 for normal knees to 192 for degenerate knees. Joints with severe degeneration (grade of 96 or greater) were excluded, as were joints where subchondral bone was exposed by full-thickness cartilage erosion.

\section{Preparation of synovial fluid}

For both cadaver and patient knees, the hSF was aspirated using a standard 18-gauge hollow bore needle attached to a $10 \mathrm{cc}$ or $60 \mathrm{cc}$ syringe. Synovial fluid was clarified of cells and debris by centrifugation at $3000 \mathrm{~g}$ for 30 minutes at $4{ }^{\circ} \mathrm{C}$ and stored at $-70{ }^{\circ} \mathrm{C}$ until use.

\section{Biochemical analysis of synovial fluid}

Portions of hSF were assayed for the concentrations of total protein and HA, as well as the $\mathrm{M}_{\mathrm{r}}$ distribution of HA.

\section{Protein concentration}

Total protein was quantified with the BCA assay (Thermo Fisher Scientific Inc, Rockford, IL, USA). A portion of SF was diluted 1:30 in water and assayed following the manufacturer's protocol. In pilot studies, the background absorbance of SF samples at that dilution (with water instead of working reagent) corresponded to an apparent protein concentration of $0.29 \pm 0.01 \mathrm{mg} / \mathrm{ml}$ (mean \pm standard error of the mean, $\mathrm{n}=30$ samples). Since this was negligible $(<2 \%)$ relative to the typical protein concentrations of SF $(17 \mathrm{mg} / \mathrm{ml})$, background was not routinely assessed.

\section{HA concentration}

The concentration of HA was determined by an enzymelinked immunosorbent assay-like assay using recombinant human aggrecan for detection (R\&D Systems, Minneapolis, MN, USA) following digestion of the protein component with proteinase $\mathrm{K}(0.5 \mathrm{mg} / \mathrm{ml})$ overnight at $37^{\circ} \mathrm{C}$ and inhibition of proteinase $\mathrm{K}$ by heating to $100{ }^{\circ} \mathrm{C}$ for $10 \mathrm{mi}$ nutes. According to the manufacturer's protocol, the assay detects HA $\mathrm{M}_{\mathrm{r}}$ forms as small as 15-40 kDa.

\section{$H A M_{r}$}

$\mathrm{M}_{\mathrm{r}}$ distribution of HA was determined using an agarose gel electrophoresis technique [23]. Briefly, hSF was treated with proteinase $\mathrm{K}$ and then heating. Sample portions with HA mass of 200-500 ng were applied to $1 \%$ agarose gels (Lonza, Rockland, ME, USA), separated by horizontal electrophoresis at $100 \mathrm{~V}$ for 110 minutes in TAE buffer (0.4 M Tris-acetate, 0.01 M EDTA, pH 8.3), and visualized by incubation with $0.1 \%$ Stainsall reagent (Sigma, St. Louis, MO, USA). Gels were imaged, and images were analyzed by comparison to $\mathrm{M}_{\mathrm{r}}$ standards to determine HA $\mathrm{M}_{\mathrm{r}}$ distribution [24]. The proportions of HA within the $\mathrm{M}_{\mathrm{r}}$ ranges of $0.03-0.5 \mathrm{MDa}, 0.5-1.0$ $\mathrm{MDa}, 1.0-2.5 \mathrm{MDa}$, and 2.5-7.0 $\mathrm{MDa}$ were calculated. The selection of $M_{r}$ bins was based on the logarithmic relationship between $\mathrm{HA} \mathrm{M}_{\mathrm{r}}$ and electrophoretic mobility and to encompass the large range of $\mathrm{HA}_{\mathrm{r}}$ [23]. The concentration of HA within each $\mathrm{M}_{\mathrm{r}}$ range was calculated as the proportion of $\mathrm{HA}$ in that range multiplied by the overall HA concentration. Since the molecular weight distribution of HA in SF is typically graded [23], the exact choice of HA $M_{r}$ bins would not be expected to affect the main results, and we chose the bins used in our previous studies $[3,25]$.

\section{Results}

hSF variation between left and right knees

Left and right knees from the same donor showed a number of similarities. Overall joint grades were low

Table 1 Agreement between properties of left and right knees of donors for overall joint grade, and hSF concentrations of protein, hyaluronan, and hyaluronan in molecular weight ranges of 2.5-7 MDa, 1-2.5 MDa, 0.5-1 MDa, and 0.03-0.25 MDa

\begin{tabular}{|c|c|c|c|c|c|c|}
\hline Measure & Mean \pm SD & Slope & Intercept & $R^{2}$ & $p$ & $n$ \\
\hline Overall joint grade & $65 \pm 14$ & $0.89 \pm 0.07$ & $5 \pm 4$ & 0.94 & 0.5 & 18 \\
\hline$C_{\text {Pro }}$ & $17 \pm 8 \mathrm{mg} / \mathrm{ml}$ & $1.02 \pm 0.06$ & $0.1 \pm 1.0 \mathrm{mg} / \mathrm{ml}$ & 0.95 & 0.45 & 18 \\
\hline $\mathrm{CHA}_{\mathrm{HA}}$ & $2.2 \pm 1.6 \mathrm{mg} / \mathrm{ml}$ & $1.0 \pm 0.2$ & $0.2 \pm 0.4 \mathrm{mg} / \mathrm{ml}$ & 0.67 & 0.74 & 15 \\
\hline $\mathrm{C}_{\mathrm{HA}(2.5-7 \mathrm{MDa})}$ & $1.6 \pm 1.2 \mathrm{mg} / \mathrm{ml}$ & $1.0 \pm 0.1$ & $0.0 \pm 0.3 \mathrm{mg} / \mathrm{ml}$ & 0.65 & 0.51 & 15 \\
\hline $\mathrm{C}_{\mathrm{HA}(1-2.5 \mathrm{MDa})}$ & $0.4 \pm 0.4 \mathrm{mg} / \mathrm{ml}$ & $0.9 \pm 0.2$ & $0.03 \pm 0.06 \mathrm{mg} / \mathrm{ml}$ & 0.69 & 0.88 & 15 \\
\hline $\mathrm{CH}_{\mathrm{H}(0.5-1 \mathrm{MDa})}$ & $0.05 \pm 0.07 \mathrm{mg} / \mathrm{ml}$ & $0.6 \pm 0.3$ & $0.01 \pm 0.01 \mathrm{mg} / \mathrm{ml}$ & 0.65 & 0.27 & 15 \\
\hline $\mathrm{C}_{\mathrm{HA}(0.03-0.5 \mathrm{MDa})}$ & $0.02 \pm 0.03 \mathrm{mg} / \mathrm{ml}$ & $1.1 \pm 0.2$ & $0.013 \pm 0.007 \mathrm{mg} / \mathrm{ml}$ & 0.88 & 0.04 & 15 \\
\hline
\end{tabular}

The mean and standard deviation (SD) of donor averaged left and right values, slope (mean \pm standard error of the mean (SEM)), intercept (mean \pm SEM), and correlation coefficient $\left(\mathrm{R}^{2}\right)$ from reduced major axis regression, $p$-value from paired t-tests and number of samples $(\mathrm{n})$ are shown. $C_{P \text { ro }}$ Concentration of protein, $C_{H A}$ Concentration of hyaluronan 
$($ mean $=65)$ and similar between right and left knees, with a slope of the reduced major axis approaching one (Table 1, Fig. 1a), a high regression coefficient $\left(R^{2}=0.94\right.$; Table 1), lack of a significant difference in paired t-tests $(p=0.5$; Table 1$)$ and most differences between left and right data points falling within the $95 \%$ limits of agreement in Bland-Altman plots (Fig. 1b). Additionally, hSF HA properties, $\mathrm{c}_{\mathrm{Pro}}, \mathrm{c}_{\mathrm{HA}}, \mathrm{c}_{\mathrm{HA}(2.5-7 \mathrm{MDa})}, \mathrm{c}_{\mathrm{HA}(1-2.5 \mathrm{MDa})}$

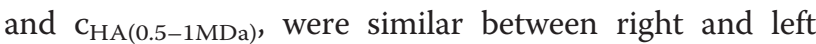
knees (Table 1), with slopes of the reduced major axis approaching one, high regression coefficients $\left(\mathrm{R}^{2}=0.65-\right.$ $0.95)$, most paired $\mathrm{t}$-tests being insignificant $(p=0.3-$ 0.9 ), and most left and right data points falling within the $95 \%$ limits of agreement. HA was mostly in higher $\mathrm{M}_{\mathrm{r}}$ fractions, with $\mathrm{C}_{\mathrm{HA}(0.03-0.5 \mathrm{MDa})}$ being low (mean = $0.02 \mathrm{mg} / \mathrm{ml}$ ). Because of the high degree of similarity
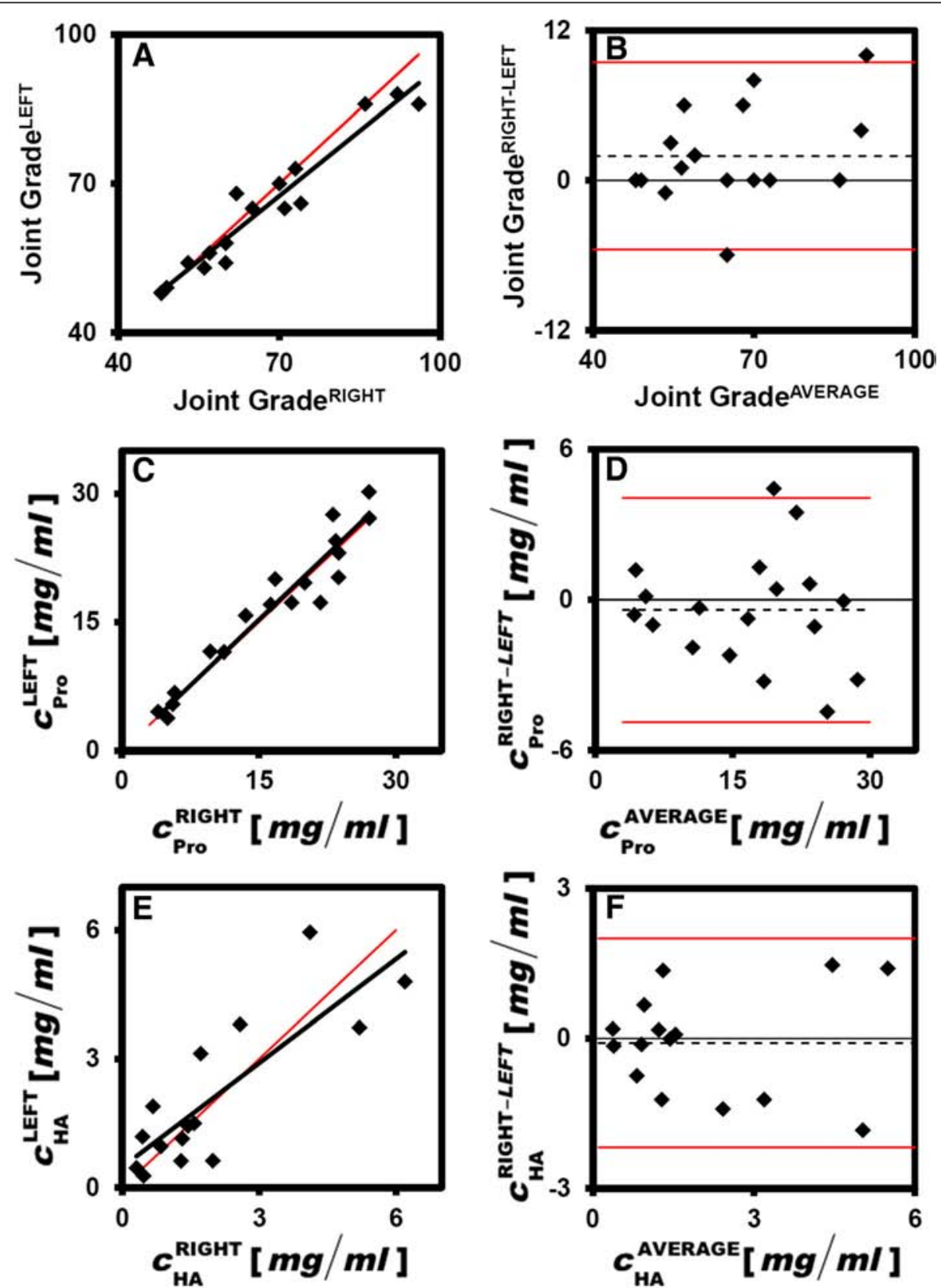

Fig. 1 Graphical representation of left and right joint similarity. Data for left (y axis) and right ( $x$ axis) knees are plotted for joint grade (a), concentration of protein $\left(c_{\text {Pro }}\right)(\mathbf{c})$, and concentration of hyaluronan $\left(c_{H A}\right)(\mathbf{e})$; the red line represents the line of perfect concordance while the black line is the reduced major axis of the data. The difference between left and right knees is plotted against the average of left and right knees for joint grade $(\mathbf{b}), c_{\text {Pro }}(\mathbf{d})$, and $\mathrm{C}_{\mathrm{HA}}(\mathbf{f})$; dashed lines represent the mean difference while red lines represent \pm two standard deviations of the individual differences. $\mathrm{n}=15-18$ donors 
between data from left and right joints, subsequent analyses were performed on data averaged from left and right knees when both were available.

\section{Similarity of age-matched patient and cadaver hSF properties}

Properties of hSF were similar between samples from age-matched patient and cadaver knee joints. The agematched samples had mean and SD of age that were similar $(p=0.84)$ for patient $(44.9 \pm 15.1$ years $(25-59$ years) and cadaver ( $45.9 \pm 13.3$ years (23-62 years)) samples. hSF from patient and cadaver knee joints were similar in $c_{\text {Pro }}(19 \pm 9 \mathrm{mg} / \mathrm{ml} ; p=0.23), \quad c_{\mathrm{HA}}(2.3 \pm$ $1.6 \mathrm{mg} / \mathrm{ml} ; p=0.20), \mathrm{C}_{\mathrm{HA}(2.5-7 \mathrm{MDa})}(1.8 \pm 1.3 \mathrm{mg} / \mathrm{ml} ; p=$ $0.53)$, and $\mathrm{C}_{\mathrm{HA}(1-2.5 \mathrm{MDa})}(0.44 \pm 0.37 \mathrm{mg} / \mathrm{ml} ; p=0.16)$, with a strong association with age (each $p<0.05$ ). At smaller HA $M_{r}$, hSF concentrations were relatively low, with patient $\mathrm{C}_{\mathrm{HA}(0.5-1 \mathrm{MDa})}(0.16 \pm 0.08 \mathrm{mg} / \mathrm{ml})$ and $\mathrm{C}_{\mathrm{HA}(0.03-0.5 \mathrm{MDa})}(0.10 \pm 0.08 \mathrm{mg} / \mathrm{ml})$ being much lower than

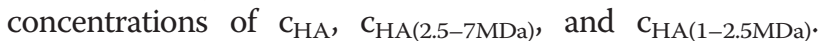
Relative to patient hSF, cadaver hSF exhibited even lower $\mathrm{c}_{\mathrm{HA}(0.5-1 \mathrm{MDa})}(-65 \%, p<0.005)$ and $\mathrm{c}_{\mathrm{HA}(0.03-0.5 \mathrm{MDa})}(-52 \%$, $p<0.05)$.

\section{Relationships of hSF properties with age}

Overall joint grade and hSF HA content exhibited strong relationships with age. Univariate linear regression revealed strong associations with age of joint grade and certain hSF biochemical properties. Joint grade was strongly associated with age $\left(\mathrm{R}^{2}=0.52 ; p<0.001\right)$, increasing by $\sim 15 \%$ per decade of age (Fig. $2 \mathrm{a}$ ). $\mathrm{C}_{\text {Pro }}$ was not related to age $(p=0.42$; Fig. $2 \mathrm{~b})$ or joint grade $(p=0.62$; Table 2). $\mathrm{c}_{\mathrm{HA}}$ had a strong relationship with age $(p<0.01$; Fig. 2c), decreasing $\sim 10.5 \%$ per decade of age, as did the concentration of $\mathrm{HA}$ in all $\mathrm{M}_{\mathrm{r}}$ bins $\left(\mathrm{c}_{\mathrm{HA}(2.5-7 \mathrm{MDa}) \text {, }}\right.$ $\mathrm{C}_{\mathrm{HA}(1-2.5 \mathrm{MDa})}, \mathrm{C}_{\mathrm{HA}(0.5-1 \mathrm{MDa})}$ and $\left.\mathrm{C}_{\mathrm{HA}(0.03-0.5 \mathrm{MDa})}\right)$, decreasing with age at rates of -9.4 to $-13 \%$ per decade of age (Fig. 3). Consistent with this, the distribution of HA was similar with age (e.g., Fig. 4) and the beta regression analysis did not detect a relationship to age of the fraction of HA in each $M_{r}$ bin $(p=0.18-0.24)$. While there was a trend toward association of hSF HA and joint grade, the relationship did not achieve statistical significance $(p=$ 0.17; Table 2), nor did $\mathrm{M}_{\mathrm{r}}$ forms of HA ( $p=0.21-0.48$; Table 2). Multivariate regression confirmed the results of univariate linear regression.

\section{Discussion}

The results of the present study delineated characteristics of HA in hSF from knees that exhibited early-stage age-associated deterioration but not OA. HA concentration was strikingly similar between left and right knees of the same cadaveric donor $\left(R^{2}=0.67\right.$; Fig. $1 c$, Table 1$)$ and decreased substantially with age $\left(R^{2}=0.21\right.$; Fig. $\left.2 c\right)$.
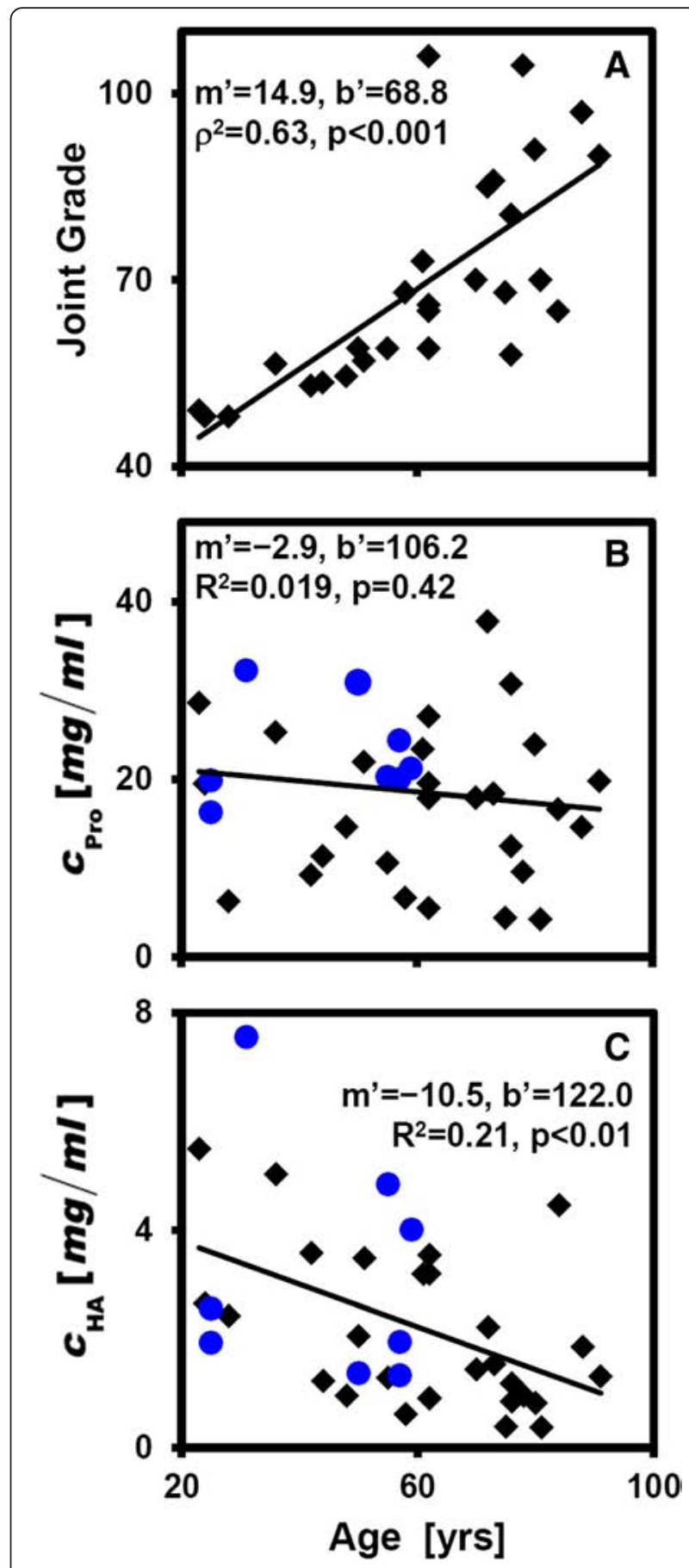

Fig. 2 Relationships with age of overall joint grade (a), concentration of protein $\left(\boldsymbol{C}_{\text {Pro }}\right)(\mathbf{b})$, and concentration of hyaluronan $\left(\boldsymbol{C}_{H A}\right)(\mathbf{c})$. Data from cadaver (black diamond) and patient joints (blue circles) are shown. Slope (in percent per decade of age) and intercept (percent) of the best-fit line in the form of $100 y / y(21)=m^{\prime}(x / 10)+b^{\prime}$, the coefficient of determination $\left(R^{2}\right)$, and significance of the regression are shown. Because of the agreement between left and right knees, statistical analyses were performed using the average of data from left and right knees from each donor, if available. $n=28-36$ donors 
Table 2 Relationships with overall joint grade of the quantities as described in Table 1

\begin{tabular}{lllll}
\hline Measure & Slope $(\mathrm{mg} / \mathrm{ml})$ & $\mathrm{R}^{2}$ & $p$ & $\mathrm{n}$ \\
\hline$C_{\text {Pro }}$ & 0.051 & 0.01 & 0.62 & 28 \\
$\mathrm{C}_{\mathrm{HA}}$ & -0.022 & 0.07 & 0.17 & 28 \\
$\mathrm{C}_{\mathrm{HA}(2.5-7 \mathrm{MDa})}$ & -0.013 & 0.04 & 0.35 & 25 \\
$\mathrm{C}_{\text {HA(1-2.5MDa) }}$ & -0.005 & 0.05 & 0.29 & 25 \\
$\mathrm{C}_{\text {HA }(0.5-1 \mathrm{MDa})}$ & -0.0006 & 0.02 & 0.48 & 25 \\
$\mathrm{C}_{\text {HA(0.03-0.5MDa) }}$ & -0.0007 & 0.07 & 0.21 & 25 \\
\hline
\end{tabular}

Because of the agreement between left and right knees, statistical analyses were performed using the average of data from left and right knees from each donor, if available. $C_{\text {Pro }}$ Concentration of protein, $C_{H A}$ Concentration of hyaluronan

HA concentration in each of the $M_{r}$ ranges studied

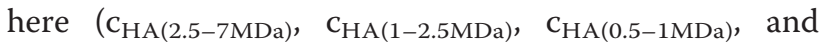
$\mathrm{C}_{\mathrm{HA}(0.03-0.5 \mathrm{MDa})}$; Fig. 3), decreased an average of $\sim 11.3 \%$ per decade of age $\left(R^{2}=0.15-0.24\right)$. Joint grade of the cadaveric joints (Fig. 2a) also varied with age, increasing 10.5\% per decade of age. There was also an inverse association between hSF HA concentration and macroscopic joint grade, although this did not achieve statistical significance $(p=0.17)$ and the $\mathrm{R}^{2}$ was low (0.07).

The assessment of the natural variation in HA concentration and $\mathrm{M}_{\mathrm{r}}$ distribution in knee hSF with age, in the absence of OA, can be affected by a number of factors. The similarity between donor left and right knees in joint grade, as well as HA biochemical properties, $\mathrm{c}_{\mathrm{HA}}$, $\mathrm{C}_{\mathrm{HA}(2.5-7 \mathrm{MDa})}, \mathrm{C}_{\mathrm{HA}(1-2.5 \mathrm{MDa})}$, and $\mathrm{C}_{\mathrm{HA}(0.5-1 \mathrm{MDa})}$, and $\mathrm{c}_{\mathrm{Pro}}$, relative to the variation between donors (Table 1) indicated that measures from paired knees should not be considered independent measures. In addition, the collection of cadaveric knee hSF 24-72 hours after death may reflect differences from the in vivo state, although concentration of hSF HA overall and in high $\mathrm{M}_{\mathrm{r}}(>1$ $\mathrm{MDa}$ ) fractions was indistinguishable between agematched samples from patients and cadaveric donors. Between the time of death and sample collection, concentrations of lower $\mathrm{M}_{\mathrm{r}}$ HA may have diminished due to local diffusion or exudation of those solutes. However, the consistencies in hSF properties between agematched patient and cadaver samples, as well as the between left and right knees of cadaver samples, suggest that the sampling method employed here provides an appropriate indicator of knee hSF status.

The age-related variation in hSF HA and protein concentrations determined here are consistent within and extend those reported previously. The hSF HA concentrations $(2.2 \pm 1.7 \mathrm{mg} / \mathrm{ml})$ are within the published range for normal knees $(0.8-3.8 \mathrm{mg} / \mathrm{ml})[13,14,26]$. The hSF protein concentrations $(17 \pm 8 \mathrm{mg} / \mathrm{ml})$ are within range of that reported previously for normal knees $(12-30 \mathrm{mg} / \mathrm{ml})$ $[26,27]$ and were not age-dependent, consistent with the joints not being arthritic or injured. The overall decrease

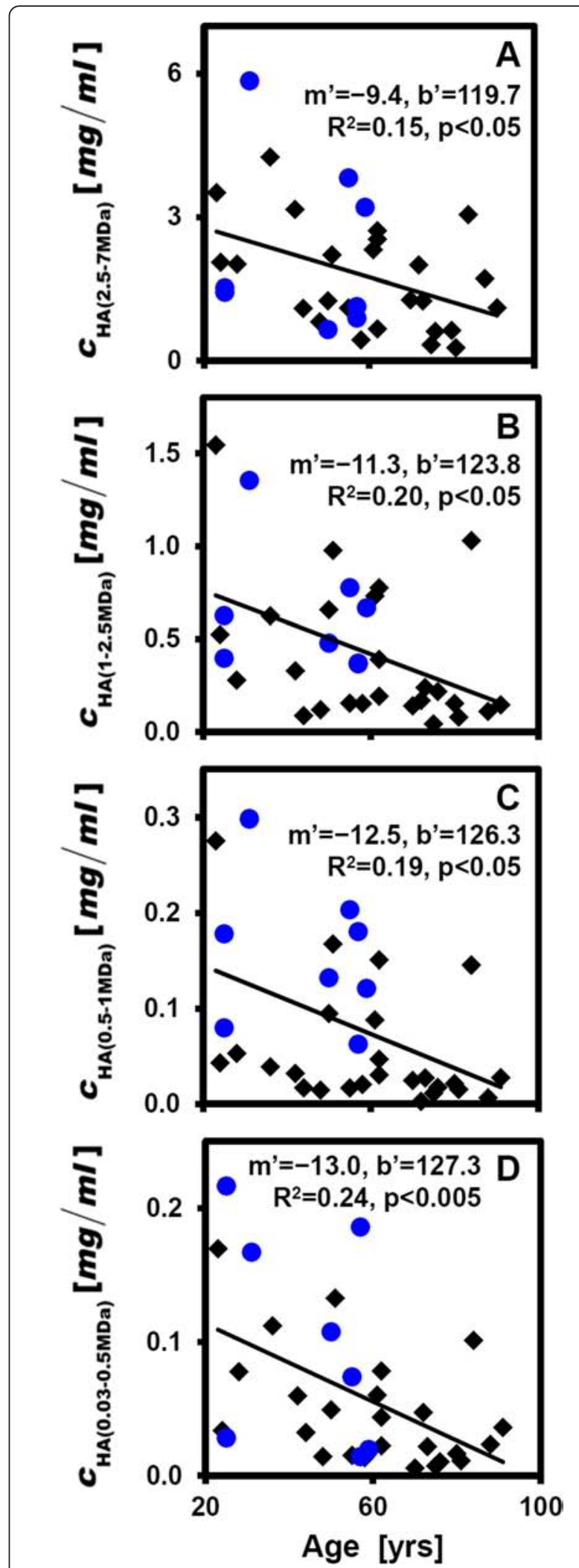

Fig. 3 Relationships with age of $\mathrm{C}_{\mathrm{HA}(2.5-7 \mathrm{MDa})}(\mathbf{a}), \mathrm{C}_{\mathrm{HA}(1-2.5 \mathrm{MDa})}(\mathbf{b})$, $\mathrm{C}_{\mathrm{HA}(0.5-1 \mathrm{MDa})}(\mathbf{c})$, and $\mathrm{C}_{\mathrm{HA}(0.03-0.5 \mathrm{MDa})}(\mathbf{d})$. Data are shown as described in Fig. 1. $n=33$. $C_{H A}$ Concentration of hyaluronan 


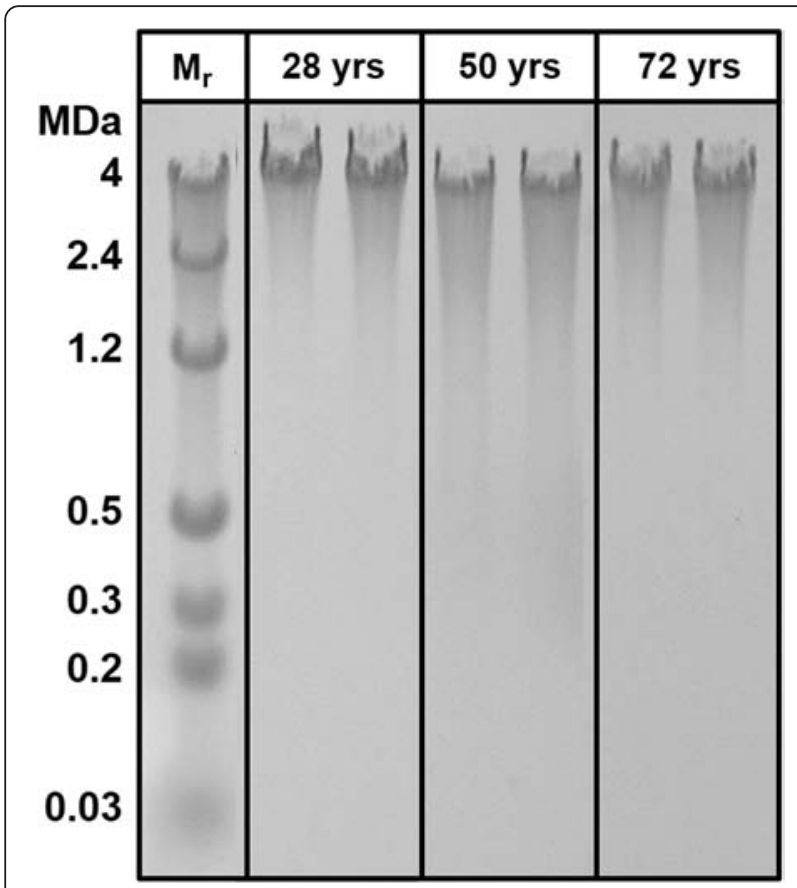

Fig. 4 Electrophoretic pattern of HA in duplicate hSF samples from a 28-year-old donor, 50 year-old-donor, and 72-year-old donor. $M_{r}$ Molecular weight mass

in HA concentration with age agrees with most studies $[14,28,29]$ but not a report that did not observe a difference between 28-35 years and 52-78 years of age although viscosity properties did shift [13]. These differences may be due to the possible confounding effects of cartilage degeneration and OA disease, donor age distribution of samples selected for the studies, or differences in the sensitivity or type of biochemical methods employed (determination of hexosamine and hexuronic acid [13, 14] vs. immunochemical assay).

The similar age-associated decrease in concentration of $\mathrm{HA}$ in each of the analyzed $\mathrm{M}_{\mathrm{r}}$ ranges is a new finding that may be particularly relevant to joint mechanics and mechanobiology. The decrease in high- $\mathrm{M}_{\mathrm{r}}(1-2.5 \mathrm{MDa}$ and 2.5-7 MDa) HA may be especially important, since these large molecules contribute primarily to boundary lubrication at articular cartilage-cartilage interfaces $[3,30]$ where HA may interact with PRG4 [10]. The age-related changes may be due to a variety of factors including HA anabolism, catabolism, and transport. The lack of variation of $M_{r}$ distribution of hSF HA with age, reflecting integrative anabolic, catabolic, and transport effects, is distinct from effects of injury [31], where high $\mathrm{M}_{\mathrm{r}} \mathrm{HA}$ is selectively lost from SF. Histological study of normal synovial membrane showed no age-dependent changes in frequency of subsynovial blood vessel crosssections, synovial intimal cells, mast cells, and subsynovial connective tissue cells [32]. On the other hand, HA degradation by hyaluronidases and reactive oxygen species generally result in HA of low $\mathrm{M}_{\mathrm{r}}(0.8-20 \mathrm{kDa})[33,34]$ that are rapidly lost from the joint [35] and can be angiogenic, inflammatory, and immunostimulatory [36]. The age-related decrease in high $\mathrm{M}_{\mathrm{r}} \mathrm{HA}$ with age may provide a target for modulation to restore hSF to young, normal lubricant molecule concentrations.

\section{Conclusions}

The concentration decrease of HA in hSF with age, in the absence of $\mathrm{OA}$, and the association of lower HA in SF with increased friction between cartilage surfaces, suggest that this relationship may be an important factor in the age-related deterioration of knee articular cartilage.

\section{Declarations}

Ethics approval and consent to participate

Human subjects included in this study were consenting patients in an Institutional Review Board (IRB) approved study at UCSD (IRB\# 071788).

\section{Consent for publication \\ Not applicable.}

\section{Availability of data and materials}

Data are available upon request from the corresponding author.

\section{Abbreviations \\ BMI: Body mass index; $\mathrm{CHA}_{\mathrm{HA}}$ : Concentration of hyaluronan; $\mathrm{CPro}_{\mathrm{ro}}$ : Concentration of protein; HA: Hyaluronan; hSF: Human synovial fluid; ICRS: International Cartilage Repair Society; $M_{r}$ : Molecular mass; OA: Osteoarthritis; SD: Standard deviation; SF: Synovial fluid; SEM: Standard error of the mean.}

\section{Competing interests}

The authors declare that they have no competing interests.

\section{Authors' contributions}

MMTW acquired data, performed data analysis, performed statistical analysis, and drafted the manuscript. SR and PQ processed samples, acquired data, and participated in data analysis. ACC, $\mathrm{AH}$, and $\mathrm{BCH}$ acquired and processed samples and acquired data. DDD and MKL participated in study design and coordination, and coordinated sample acquisition and analysis. JK made contributions to the analysis and interpretation of data. KM participated in study design and data acquisition. RLS conceived of the study, participated in study design and coordination, and helped draft the manuscript. All authors read and contributed to manuscript drafts, and approved the final manuscript.

\section{Acknowledgements}

This work was supported by research grants from the National Institutes of Health. The funding body did not participate in the design of the study, collection, analysis, and interpretation of data, or in writing the manuscript.

\section{Author details}

'Department of Bioengineering, University of California-San Diego, 9500 Gilman Drive, Mail Code 0412, La Jolla, CA 92093-0412, USA. ²Department of Molecular and Experimental Medicine, MEM-161, The Scripps Research Institute, 10550 North Torrey Pines Road, La Jolla, CA 92037, USA. 'Shiley Center for Orthopaedic Research \& Education at Scripps Clinic, 10550 North Torrey Pines Road, La Jolla, CA 92037, USA. "Department of Orthopaedic Surgery, University of California-San Diego, 9500 Gilman Drive, Mail Code 0412, La Jolla, CA 92093-0412, USA. ${ }^{5}$ Center for Musculoskeletal Research, 
Institute of Engineering in Medicine, University of California-San Diego, 9500 Gilman Drive, Mail Code 0412, La Jolla, CA 92093-0412, USA.

Received: 6 October 2015 Accepted: 5 January 2016

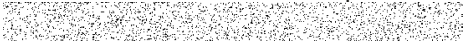

\section{References}

1. Schmidt TA, Sah RL. Effect of synovial fluid on boundary lubrication of articular cartilage. Osteoarthritis Cartilage. 2007;15:35-47.

2. Temple MM, Bae WC, Chen MQ, Lotz M, Amiel D, Coutts RD, et al. Age- and site-associated biomechanical weakening of human articular cartilage of the femoral condyle. Osteoarthritis Cartilage. 2007;15:1042-52.

3. Antonacci JM, Schmidt TA, Serventi LA, Cai MZ, Shu YL, Schumacher BL, et al. Effects of equine joint injury on boundary lubrication of articular cartilage by synovial fluid: role of hyaluronan. Arthritis Rheum. 2012;64:2917-26.

4. Ballard BL, Antonacci JM, Temple-Wong MM, Hui AY, Schumacher BL, Bugbee WD, et al. Effect of tibial plateau frracture on lubrication function and composition of synovial fluid. J Bone Joint Surg Am. 2012;94:64(61-69).

5. Elsaid KA, Jay GD, Warman ML, Rhee DK, Chichester CO. Association of articular cartilage degradation and loss of boundary-lubricating ability of synovial fluid following injury and inflammatory arthritis. Arthritis Rheum. 2005:52(6):1746-55.

6. Teeple E, Elsaid KA, Fleming BC, Jay GD, Aslani K, Crisco JJ, et al. Coefficients of friction, lubricin, and cartilage damage in the anterior cruciate ligament-deficient guinea pig knee. J Orthop Res. 2008;26(2):231-7.

7. Zea-Aragon Z, Ohtsuki K, Ohnishi M, Ohno S. Immunohistochemical study of the upper surface layer in rat mandibular condylar cartilage. Histol Histopathol. 2004:19(1):29-36.

8. Meyer $\mathrm{K}$, Smyth EM, Dawson MH. The isolation of a mucopolysaccharide from synovial fluid. J Biol Chem. 1939;128(1):319-27.

9. Bonnevie ED, Galesso D, Secchieri C, Cohen I, Bonassar L. Elastoviscous transitions of articular cartilage reveal a mechanism of synergy between lubricin and hyaluronic acid. PLoS One. 2015;10(11):e0143415.

10. Das S, Banquy X, Zappone B, Greene GW, Jay GD, Israelachvili JN. Synergistic interactions between grafted hyaluronic acid and lubricin provide enhanced wear protection and lubrication. Biomacromolecules. 2013;14(5):1669-77.

11. Schmidt TA, Gastelum NS, Nguyen QT, Schumacher BL, Sah RL. Boundary lubrication of articular cartilage: role of synovial fluid constituents. Arthritis Rheum. 2007;56:882-91.

12. Mazzucco D, Scott R, Spector M. Composition of joint fluid in patients undergoing total knee replacement and revision arthroplasty: correlation with flow properties. Biomaterials. 2004;25(18):4433-45.

13. Balazs EA. The physical properties of synovial fluid and the special role of hyaluronic acid. In: Helfet AJ, editor. Disorders of the Knee. Philadelphia: Lippincott Co; 1974. p. 63-75.

14. Hamerman D, Schuster H. Hyaluronate in normal human synovial fluid. J Clin Invest. 1958:37(1):57-64.

15. Belcher C, Yaqub R, Fawthrop F, Bayliss M, Doherty M. Synovial fluid chondroitin and keratan sulphate epitopes, glycosaminoglycans, and hyaluronan in arthritic and normal knees. Ann Rheum Dis. 1997;56(5):299-307.

16. Temple-Wong MM, Hansen BC, Grissom MJ, Cai MZ, Noori NB, Roberts JM, et al. Effects of knee osteoarthritis on the boundary lubricating molecules and function of human synovial fluid. Trans Orthop Res Soc. 2010;35:340.

17. Sokal RR, Rohlf FJ. Biometry. 3rd ed. New York: WH Freeman and Co.; 1995.

18. Weir BS. Genetic data analysis: methods for discrete population genetic data. Sunderland, MA: Sinauer Associates; 1990

19. Altman DG, Bland JM. Measurement in Medicine - the Analysis of Method Comparison Studies. Statistician. 1983;32(3):307-17.

20. Team R Core. R: A language and environment for statistical computing. Vienna, Austria: R Foundation for Statistical Computing; 2014. [https://www. r-project.org/].

21. Mankin HJ, Dorfman H, Lipiello L, Zarins A. Biochemical and metabolic abnormalities in articular cartilage from osteoarthritic human hips. II. Correlation of morphology with biochemical and metabolic data. J Bone Joint Surg Am. 1971;53-A:523-37.

22. Outerbridge RE. The etiology of chondromalacia patellae. J Bone Joint Surg Br. 1961;43-B:752-7.

23. Lee HG, Cowman MK. An agarose gel electrophoretic method for analysis of hyaluronan molecular weight distribution. Anal Biochem. 1994;219(2):278-87.
24. Blewis ME, Lao BJ, Jadin KD, McCarty WJ, Bugbee WD, Firestein GS, et al. Semipermeable membrane retention of synovial fluid lubricants hyaluronan and proteoglycan 4 for a biomimetic bioreactor. Biotechnol Bioeng. 2010;106:149-60.

25. Grissom MJ, Temple-Wong MM, Adams MS, Tom M, Schumacher BL, Mcllwraith CW, et al. Synovial fluid lubricant properties are transiently deficient after arthroscopic articular cartilage defect repair with platelet-enriched fibrin alone and with mesenchymal stem cells. Orthop J Sports Med. 2014;2:2325967114542580.

26. Balazs EA, Watson D, Duff IF, Roseman S. Hyaluronic acid in synovial fluid. I. Molecular parameters of hyaluronic acid in normal and arthritis human fluids. Arthritis Rheum. 1967:10(4):357-76.

27. McCarty DJ. Synovial fluid. In: Koopman WJ, editor. Arthritis and Allied Conditions: A Textbook of Rheumatology, vol. 1. 13th ed. Baltimore, MD: Williams \& Wilkins; 1997. p. 81-102.

28. Uesaka S, Miyazaki K, Ito H. Age-related changes and sex differences in chondroitin sulfate isomers and hyaluronic acid in normal synovial fluid. Mod Rheumatol. 2004;14(6):470-5.

29. Nakayama $Y$, Narita T, Mori A, Uesaka S, Miyazaki $K$, Ito $H$. The effects of age and sex on chondroitin sulfates in normal synovial fluid. Arthritis Rheum. 2002:46(8):2105-8

30. Kwiecinski JJ, Dorosz SG, Ludwig TE, Abubacker S, Cowman MK, Schmidt TA. The effect of molecular weight on hyaluronan's cartilage boundary lubricating ability - alone and in combination with proteoglycan 4. Osteoarthritis Cartilage. 2011;19(11):1356-62.

31. McCarty WJ, Cheng JC, Hansen BC, Yamaguchi T, Masuda K, Sah RL. The biophysical mechanisms of altered hyaluronan concentration in synovial fluid after anterior cruciate ligament transection. Arthritis Rheum. 2012;64:3993-4003.

32. Castor $\mathrm{CW}$. The microscopic structure of normal human synovial tissue. Arthritis Rheum. 1960;3:140-51.

33. Stern R, Kogan $G$, Jedrzejas MJ, Soltes $L$. The many ways to cleave hyaluronan. Biotechnol Adv. 2007;25(6):537-57.

34. Lepperdinger G, Strobl B, Kreil G. HYAL2, a human gene expressed in many cells, encodes a lysosomal hyaluronidase with a novel type of specificity. J Biol Chem. 1998;273(35):22466-70.

35. Levick JR. An analysis of the interaction between interstitial plasma protein, interstitial flow, and fenestral filtration and its application to synovium. Microvasc Res. 1994:47(1):90-125.

36. Powell JD, Horton MR. Threat matrix: low-molecular-weight hyaluronan (HA) as a danger signal. Immunol Res. 2005:31(3):207-18.

\section{Submit your next manuscript to BioMed Central and we will help you at every step:}

- We accept pre-submission inquiries

- Our selector tool helps you to find the most relevant journal

- We provide round the clock customer support

- Convenient online submission

- Thorough peer review

- Inclusion in PubMed and all major indexing services

- Maximum visibility for your research

Submit your manuscript at www.biomedcentral.com/submit 